\title{
The Unity of Science: Two Hundred Years of Controversy
}

\author{
By: Creath, Richard
}

Contemporary philosophers and historians of science are often tempted to read the unity of science movement of the 1920s and 30s as insisting that all of the sciences should be "just like physics" in all details of method, ontology, and concepts. This reading locates the issue as pitting what we call the natural sciences narrowly conceived against what we call the social sciences. This caricature misses the point. A better reading of the unity of science movement understands it as responding to specific challenges to science as a whole. This challenge comes from writers who see themselves as altogether outside what we usually take to be science, that is, from broadly humanistic writers. So conceived, the unity of science movement is but one stage in a controversy that runs for at least two hundred years from the rise of romantic idealism in the early nineteenth century to today's faculty meetings throughout the academy. This paper will explore the specific historical traditions to which the unity of science movement was responding. It will also show that this nuanced picture of that movement was doing is more illuminating than the standard caricature could ever be about enduring philosophical questions concerning the relations among the sciences and between science and other human intellectual endeavors. 